\title{
A química e a tecnologia do doce de leite: uma revisão
}

\author{
The chemistry and technology of dulce de leche: a review \\ La química y la tecnología del dulce de leche: una revisión
}

Recebido: 13/08/2021 | Revisado: 22/08/2021 | Aceito: 24/08/2021 | Publicado: 12/09/2021

\author{
Lauren Carvalho Montalvão Carneiro \\ ORCID: https://orcid.org/0000-0002-5978-0094 \\ Universidade Federal de Viçosa, Brasil \\ E-mail: lauren.cmontalvao@gmail.com \\ Caroline Barroso dos Anjos Pinto \\ ORCID: https://orcid.org/0000-0002-5914-5007 \\ Universidade Federal de Juiz de Fora, Brasil \\ E-mail: caroline-barroso@ hotmail.com \\ Elisângela Ramieres Gomes \\ ORCID: https://orcid.org/0000-0002-0010-3945 \\ Universidade Federal de Viçosa, Brasil \\ E-mail: elisangelaramieres@yahoo.com.br \\ Igor Lima de Paula \\ ORCID: https://orcid.org/0000-0002-7209-3846 \\ Universidade Federal de Juiz de Fora, Brasil \\ E-mail: limaygor1996@gmail.com \\ Alan Frederick Wolfschoon Pombo \\ ORCID: https://orcid.org/0000-0002-8198-7059 \\ Inovaleite - Grupo de Pesquisa Multicêntrico, Alemanha \\ E-mail: awolfschoon@googlemail.com \\ Rodrigo Stephani \\ ORCID: https://orcid.org/0000-0003-0237-8325 \\ Universidade Federal de Juiz de Fora, Brasil \\ E-mail: rodrigostephani@gmail.com \\ Antônio Fernandes Carvalho \\ ORCID: https://orcid.org/0000-0002-3238-936X \\ Universidade Federal de Viçosa, Brasil \\ E-mail: afc1800@yahoo.com \\ Italo Perrone \\ ORCID: https://orcid.org/0000-0002-3393-4876 \\ Universidade Federal de Juiz de Fora, Brasil \\ E-mail: italotulerperrone@gmail.com
}

\begin{abstract}
Resumo
O doce de leite, sobremesa láctea altamente consumida nos países latino americanos, é obtido a partir da evaporação da água do leite adicionado de açúcar. O tratamento térmico associado a evaporação desencadeia diversas alterações químicas que influenciam diretamente nas características do produto final. Apesar de possuir poucos ingredientes na sua formulação, o produto final pode apresentar características bem distintas dependendo das condições de processamento e dos atributos controlados. Diante disso, fica evidente que o conhecimento de temas como capacidade tamponante do leite, a utilização de reguladores de acidez na tecnologia de fabricação do doce, reação de Maillard e os principais fatores que afetam a sua ocorrência, reologia e textura, são de extrema importância na fabricação de doce de leite. O objetivo desse artigo é apresentar as principais reações químicas envolvidas no processamento do doce de leite e relacioná-las com as características obtidas no produto.
\end{abstract}

Palavras-chave: Doce de leite; Capacidade tamponante; Reação de Maillard; Reologia; Textura.

\begin{abstract}
Dulce de leche, a dairy dessert highly consumed in Latin American countries, is obtained from the evaporation of water from milk added with sugar. The heat treatment associated with evaporation triggers several chemical changes that directly influence the characteristics of the final product. Despite having few ingredients in its formulation, the final product can present very different characteristics depending on the processing conditions and of the controlled parameters. Therefore, it is evident that knowledge of topics such as the buffering capacity of milk, the use of acidity regulators, Maillard reaction and the main factors that affect its occurrence, rheology and texture, are extremely important in the manufacture of dulce de leche. The purpose of article is to review the main chemical reactions involved in the processing of dulce de leche and relate them to the characteristics obtained in the product.
\end{abstract}

Keywords: Dulce de leche; Buffering capacity; Maillard Reaction; Rheology; Texture. 


\section{Resumen}

El dulce de leche, postre lácteo muy consumido en los países de América Latina, se obtiene de la evaporación del agua de leche añadida con azúcar. El tratamiento térmico asociado a la evaporación desencadena varios cambios químicos que influyen directamente en las características del producto final. A pesar de tener pocos ingredientes en su formulación, el producto final puede presentar características muy diferentes según las condiciones de procesamiento y de los parámetros controlados. Por tanto, es evidente que el conocimiento de temas como la capacidad amortiguadora de la leche, el uso de reguladores de acidez, la reacción de Maillard y los principales factores que inciden en su ocurrencia, reología y textura, son de suma importancia en la fabricación de dulce de leche. El propósito de este artículo es las principales reacciones químicas involucradas en el procesamiento del dulce de leche y relacionarlas con las características obtenidas en el producto.

Palabras clave: Dulce de leche; Capacidad amortiguadora; Reacción de Maillard; Reologia; Textura.

\section{Introdução}

O tratamento térmico associado à evaporação durante o processo de fabricação do doce de leite (DL) desencadeia diversas alterações químicas que possuem importante papel nas características do produto final. O objetivo desse artigo é revisar as reações químicas envolvidas no processamento do DL e relacioná-las com as características do produto.

De acordo com a Portaria n 354, de 4 de setembro de 1997, do Ministério da Agricultura, Pecuária e Abastecimento, que aprova o Regulamento Técnico de Identidade e Qualidade de Doce de Leite, “entende-se por Doce de Leite o produto, com ou sem adição de outras substâncias alimentícias, obtido por concentração e ação do calor a pressão normal ou reduzida do leite ou leite reconstituído, com ou sem adição de sólidos de origem láctea e/ou creme adicionado de sacarose (parcialmente substituída ou não por monossacarídeos e/ou outros dissacarídeos)”.

Como requisitos físico-químicos, o DL deve apresentar teor de matéria gorda entre 6 e $9 \mathrm{~g} \cdot 100 \mathrm{~g}-1$, teor de proteínas de no mínimo 5 g·100g-1, teor de cinzas de no máximo 2g·100g-1 e umidade máxima de 30g·100g-1 (Brasil, 1997a).

O DL pode ser fabricado nas formas de DL em pasta ou em barra. Na obtenção do DL em pasta é empregada menor quantidade de sacarose e o produto final apresenta-se não cristalizado e com textura pastosa e uniforme. No que diz respeito ao DL em barra, maior quantidade de sacarose é utilizada no processo de fabricação e é aplicada a técnica de bateção a fim de induzir a cristalização da lactose e sacarose, obtendo-se um produto de textura sólida (forma de blocos) (Stephani, Francisquini, Perrone, Carvalho \& Oliveira, 2019). Outro produto lácteo obtido a partir da evaporação de água do leite é o leite condensado. O leite condensado é produzido a partir da concentração do leite adicionado de sacarose seguido de resfriamento e adição de cristais de lactose (indução da cristalização). Variações nas etapas do processamento resultam em diferentes características do produto final (Tan, 2009).

Uma comparação entre a composição do leite integral, DL em barra, DL em pasta e leite condensado é ilustrada a partir da Figura 1. 
Figura 1. Comparativo entre a composição de leite integral, DL em barra, DL em pasta e leite condensado.

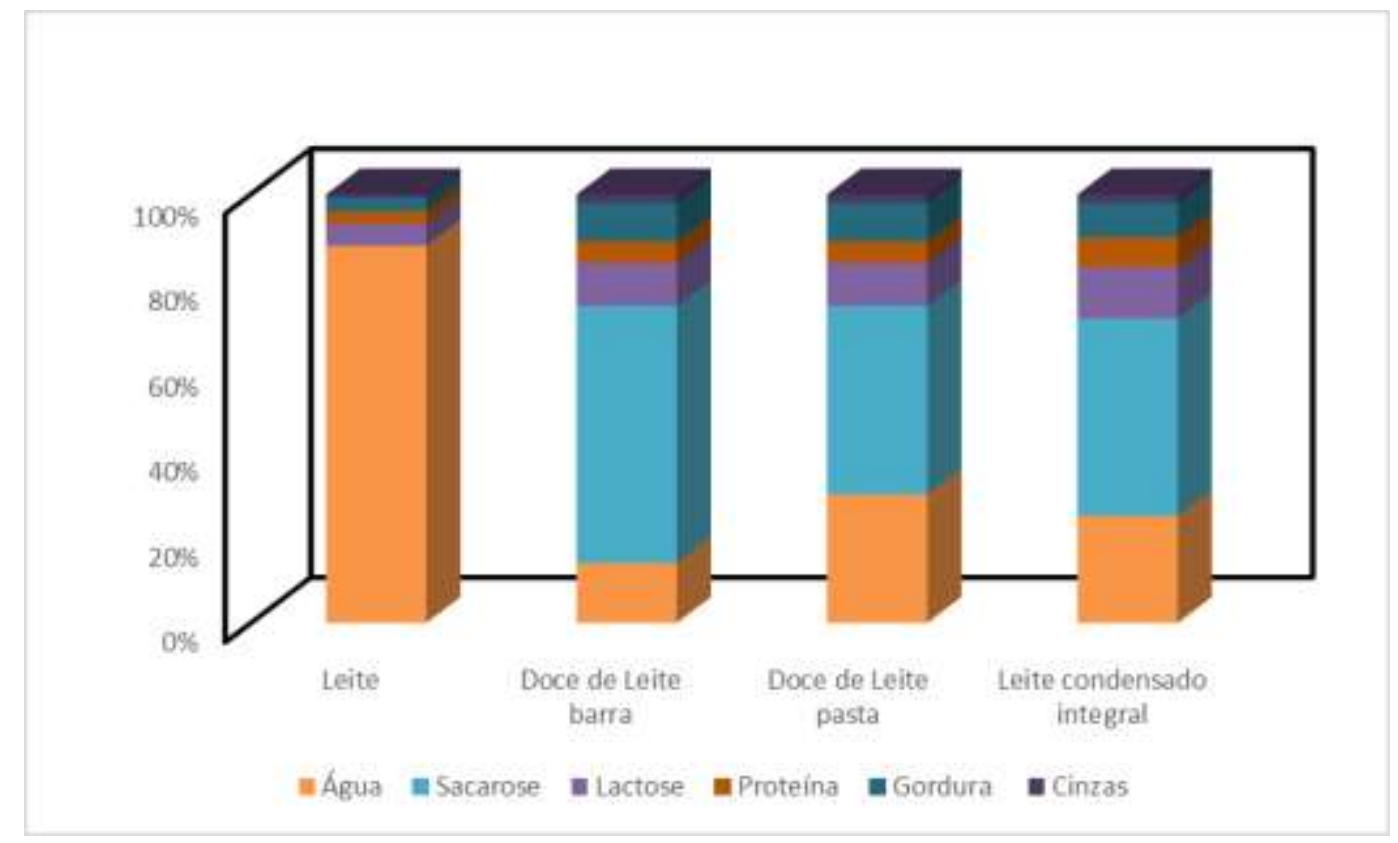

Fonte: Autores.

O leite, principal matéria prima dos lácteos concentrados, é composto predominantemente por água (cerca de 87,5\%), lactose, gordura, proteínas e cinzas. Grande parte dessa água é removida no processo de evaporação durante a fabricação dos concentrados lácteos. Comparando-se o doce de leite em pasta e o doce de leite em barra, percebe-se que a principal diferença se dá no teor de sólidos totais e sacarose (maior no doce em barra). O leite condensado e o doce de leite em pasta, apesar da composição semelhante, apresentam características distintas devido ao processo de fabricação utilizado em cada um deles (Stephani et al., 2019).

O DL é um produto lácteo de alto consumo nos países latino americanos, principalmente Brasil e Argentina, onde são também tradicionalmente fabricados (Francisquini et al., 2019). Para a fabricação do DL, o leite adicionado de sacarose passa pelo processo de evaporação no qual ocorre a remoção de água através do fornecimento de energia na forma de calor a pressão atmosférica, ou reduzida até atingir o teor de sólidos de 68-70 ${ }^{\circ}$ Brix. Apesar de envolver poucos ingredientes e aditivos na sua produção, o doce pode apresentar características completamente diferentes dependendo da tecnologia aplicada, por isso, é de extrema importância o controle dos atributos de processo como tempo, intensidade do aquecimento e pressão (Gaze et al., 2015; Ranalli, Andrés \& Califano, 2011).

O processo de fabricação do DL se inicia com a mistura dos ingredientes. O leite é o ingrediente responsável por fornecer a maior parte dos sólidos para o produto, por isso, é importante que o leite utilizado tenha preferencialmente alto teor de extrato seco total. Normalmente, utiliza-se leite integral na produção de DL. O leite desnatado também pode ser utilizado, porém, sabe-se que o teor de gordura do leite também é um fator relevante, pois confere brilho, consistência e palatabilidade ao doce. Outra alternativa é utilizar o leite concentrado com o intuito de acelerar o tempo de fabricação. (Penci \& Marín, 2016; Stephani et al., 2019).

Outro principal ingrediente utilizado na fabricação de DL é a sacarose. Por não ser um açúcar redutor, a sacarose não tem influência na reação de escurecimento não-enzimático (Reação de Maillard) do leite. Alternativamente, outros açúcares podem ser utilizados em substituição parcial da sacarose, como por exemplo, a glicose. A glicose confere características como brilho, sabor doce suave, reduz a formação de cristais, além de intensificar a reação de Maillard por ser um açúcar redutor (Penci \& Marín, 2016; Ranalli et al., 2011). 
Destaca-se também como essencial na fabricação de DL, o coadjuvante de tecnologia bicarbonato de sódio, que atua como redutor de acidez, evitando a precipitação de proteínas e favorecendo a ocorrência da Reação de Maillard (Stephani $e t$ al., 2019). Outros ingredientes podem ser opcionalmente utilizados na fabricação de DL como creme, amido, soro de leite, frutas ou outros produtos alimentícios, além de aditivos e coadjuvantes, desde que esteja de acordo com a legislação vigente (Brasil, 1997a).

$\mathrm{O}$ aquecimento a altas temperaturas por um longo período de tempo, aliado à evaporação da água do leite, gera modificações importantes durante o processo de fabricação do DL, como mostra a Tabela 1.

Tabela 1. Principais modificações causadas pelo aquecimento durante o processo de fabricação do doce de leite e suas consequências.

Principais modificações durante o aquecimento e concentração

\section{Principais Consequências}

\begin{tabular}{cc}
\hline Reação de Maillard & $\begin{array}{c}\text { Desenvolvimento de cor, } \\
\text { sabor, aroma, textura }\end{array}$ \\
\hline $\begin{array}{c}\text { Lactolização, desfosforilação da caseína, precipitação } \\
\text { de sais de cálcio, concentração da acidez natural do leite }\end{array}$ & $\begin{array}{c}\text { Acidez total desenvolvida, } \\
\text { Diminuição do pH }\end{array}$ \\
\hline Diminuição da atividade de água & Conservação \\
\hline Desnaturação das proteínas & Viscosidade \\
\hline Saturação da lactose e sacarose & Cristalização \\
\hline
\end{tabular}

Fonte: Stephani et al. (2019).

$\mathrm{O}$ aquecimento combinado a outras condições que veremos detalhadamente no decorrer do trabalho, propiciam a ocorrência da Reação de Maillard, que influencia no desenvolvimento da cor, sabor, aroma e textura do doce. A alta temperatura é responsável também pela desnaturação das proteínas, influenciando na viscosidade do produto. A concentração aliada ao aquecimento provoca a lactolização, desfosforilação da caseína, precipitação de sais de cálcio e concentração da acidez natural do leite, fatores que ocasionam a diminuição do $\mathrm{pH}$ e aumento da acidez (acidez total desenvolvida). A evaporação da água do leite adicionado de sacarose faz com que a haja a diminuição da atividade de água do produto, auxiliando na conservação. Além disso, a evaporação da água favorece a saturação da lactose e sacarose, tendo como consequência a cristalização (Stephani et al., 2019).

\section{Metodologia}

O presente trabalho trata-se de uma revisão de literatura realizada a partir de pesquisa bibliográfica em confiáveis bases de dados científicos como Science Direct, Scopus, Wiley Online Library e Scielo. Para a busca dos artigos científicos foram utilizados temos como "dulce de leche", "Maillard reaction", "dulce de leche rheology", "dulce de leche texture", "buffering capacity", "acidity regulator" e "sandiness". Critérios como artigos em sua maioria em língua inglesa e preferencialmente publicados entre os anos de 2015 a 2021 foram adotados para a seleção das publicações mais relevantes sobre doce de leite, características do produto, processo de fabricação e reações envolvidas durante a fabricação. 


\section{Resultados e discussão}

\subsection{Reação de Maillard}

Durante o aquecimento do leite e sacarose para a fabricação do DL, uma importante reação é desencadeada: a reação de Maillard (RM) (Stephani et al., 2019). A RM é uma reação complexa que ocorre entre um açúcar redutor e um grupamento amina de aminoácidos, peptídeos e proteínas, sob determinadas condições de pH, temperatura e atividade de água (Starowicz \& Zieliński, 2019). A RM tem influência no desenvolvimento de características sensoriais como cor, sabor, aroma e textura. Além disso, o valor nutricional dos alimentos pode ser alterado pelos produtos da RM através da redução da digestibilidade de proteínas, perda de alguns aminoácidos e produção de compostos tóxicos e inibidores (Damodaran; Parkin \& Fennema, 2008, Nooshkam; Varidi \& Bashash, 2019).

As substâncias responsáveis pela formação de aromas e sabor nos alimentos que sofrem a RM são as moléculas que contem oxigênio, nitrogênio ou enxofre. No caso do DL, essas substâncias são o 2-metilfurano, 2-furanmetanol, furfural e butirilactona. A influência da reação na textura está relacionada com a formação de reticulação de proteínas, propriedades de emulsões ou formação de conjugados proteína-polissacarídeos (Starowicz \& Zieliński, 2019).

O açúcar e o regulador de acidez possuem forte influência na ocorrência da reação, portanto, o tipo e a quantidade desses ingredientes a serem utilizados são muito relevantes (Stephani et al., 2019).

Segundo Nooshkam et al. (2019), a RM ocorre em três estágios: estágio inicial, intermediário e final. Na etapa inicial ocorre a condensação do grupo carbonila do açúcar redutor com o grupamento amina de aminoácidos, peptídeos ou proteínas através do ataque nucleofílico do par de elétrons do nitrogênio do grupo amina, formando a base de Schiff. A base de Schiff libera moléculas de água, formando a N-glicosilamina que sofre diferentes rearranjos de acordo com a natureza do açúcar redutor envolvido na reação. O carboidrato com grupo aldose leva à formação do produto de Amadori e com o grupo cetose leva à formação do produto de Heyns. A formação desses compostos é irreversível e não provoca alteração de sabor, cor, fluorescência e toxicidade (Bertrand, Boustany, Faulds \& Berdagué, 2018; Francisquini et al., 2017).

$\mathrm{Na}$ fase intermediária, a degradação dos compostos de Amadori ou Heyns ocorre por diferentes vias de acordo com o pH do meio. Em pH básico (pH > 7,0), a degradação realiza-se pela via de desidratação moderada ou 2,3-enolização a partir da qual duas moléculas de água são perdidas, levando a formação de compostos dicarbonílicos e produtos da degradação de Strecker. Em pH neutro ou ácido $(\mathrm{pH}<7,0)$, a degradação dos compostos dá-se pela via de forte desidratação ou 1,2enolização, sendo perdidas três moléculas de água. A partir dessa via são formados o 5-hidroximetilfurfural (hexose), furfural (pentose) e redutonas. Os compostos desenvolvidos na fase intermediária apresentam fluorescência e absorção na região ultravioleta (Bertrand et al., 2018; Nooshkam et al., 2019).

Ao final da RM, os compostos formados na etapa intermediária são polimerizados resultando na formação de melanoidinas de alto peso molecular, pigmentos escuros responsáveis pela alteração da cor dos produtos (Pinto \& WolfschonPombo, 1984; Bertrand et al., 2018).

De acordo com Damodaran et al. (2008), diversos fatores podem influenciar na velocidade da RM, incluindo temperatura, $\mathrm{pH}$, atividade de água (aw), reatividade dos açúcares e aminoácidos e presença de inibidores. A RM pode ocorrer em temperaturas mais baixas, porém com velocidade mais lenta ou em temperaturas mais elevadas, com maior velocidade. Isso explica o fato de a reação acontecer durante o aquecimento e armazenamento do produto. A cada incremento de $10{ }^{\circ} \mathrm{C}$ na faixa entre $40{ }^{\circ} \mathrm{C}$ e $70{ }^{\circ} \mathrm{C}$ a velocidade da reação é duplicada. A temperatura interfere na composição e na intensidade da coloração formada (Damodaran et al., 2008; Francisquini et al., 2017).

$\mathrm{O}$ pH do meio influencia na velocidade da RM através da alteração da reatividade dos aminoácidos. Para que ocorra a adição nucleofílica da função amina ao grupo carbonila na primeira etapa da reação, o par de elétrons do grupo amina deve estar livre para reagir. Em valores baixos de pH, os íons $\mathrm{H}+$ presentes protonam o par de elétrons, impedindo a reação. A 
reação é favorecida em pH alcalino e tem sua velocidade máxima na faixa entre 9 e 10 de pH (Bertrand et al., 2018; Damodaran et al., 2008).

A velocidade da RM é máxima em valores intermediários de atividade de água (entre 0,4 e 0,8), uma vez que a atividade de água muito baixa diminui a mobilidade dos reagentes e, em contrapartida, valores muito altos fazem com que ocorra a diluição dos reagentes (Lund \& Ray, 2017). A reatividade dos açúcares envolvidos na reação influencia fortemente no desenvolvimento da RM, sendo que as pentoses são mais reativas, seguidas das hexoses e dissacarídeos (Bertrand et al., 2018). A ocorrência da RM também é afetada pela reatividade dos aminoácidos envolvidos. A lisina é um aminoácido de alta reatividade, pois apresenta grupo amina épsilon livre (Damodaran et al., 2008; Francisquini et al., 2017). A presença de inibidores como, por exemplo, o dióxido de enxofre pode impossibilitar a reação através do bloqueio do grupo carbonila do açúcar redutor, impedindo a reação entre o açúcar redutor e o grupo amina (Damodaran et al., 2008).

A extensão da RM pode ser monitorada através da determinação do índice de 5-hidroximetilfurfural, que é facilmente detectado por espectrofotometria. O HMF é um dos produtos formados na etapa intermediária da RM e pode ser utilizado com indicador de tratamentos térmicos intensos. O HMF não está presente naturalmente nos alimentos, mas pode ser desenvolvido principalmente em alimentos com alto teor de lipídeos e carboidratos quando submetidos a tratamento térmico e armazenamento prolongado. Esse componente está relacionado com a inibição de crescimento celular, redução da digestibilidade e absorção de proteínas, redução de atividades enzimáticas e perdas nutricionais. O HMF livre (determinado sem aquecimento) e o HMF total (substâncias que se formam na presença de aquecimento e reagem com o ácido tiobarbitúrico) podem ser determinados nos alimentos (Pinto \& Wolfschon-Pombo, 1984). O HMF total possibilita presumir o quanto a reação de formação desse composto pode prosseguir. Além disso, o índice de HMF pode ser relacionado com atributos tecnológicos e sensoriais de DL (Francisquini et al., 2019).

\subsection{Capacidade tamponante}

$\mathrm{Na}$ indústria de laticínios, diversos processos tecnológicos envolvem variações no $\mathrm{pH}$ como, por exemplo, a fabricação de iogurte, queijos, leites fermentados e processos que envolvem tratamentos térmicos. A acidificação do leite faz com que ocorra a protonação de grupos ácidos e desmineralização das caseínas, diminuindo a solubilidade, hidratação e o potencial zeta dessas proteínas. Esses fatores são responsáveis pela precipitação e gelificação do leite. Ao ser submetido a tratamentos térmicos, o pH do leite é reduzido devido à degradação da lactose, desfosforilação da caseína e precipitação do fosfato de cálcio. A alcalinização é menos frequente na indústria, podendo ser utilizada na obtenção de caseinato de sódio ou cálcio a partir de caseína ácida. $\mathrm{O}$ aumento do $\mathrm{pH}$ também pode ser observado durante a maturação de queijos devido à degradação do ácido lático e à produção de amônia por microrganismos (Salaün, Mietton \& Gaucheron, 2005).

Dessa forma, uma relevante característica físico-química para o processamento de produtos lácteos é a capacidade tamponante do leite, uma vez que fornece uma resistência natural à acidificação e alcalinização, sendo elas desejadas ou não (Kirchmeier, 1980; Salaün et al., 2005; Wolfschoon-Pombo, Böttger \& Lösche, 2012; Wolfschoon-Pombo, Spiegel \& Hernandez-ZeniL, 2017). A capacidade tamponante é definida como a quantidade necessária de um ácido ou base a uma determinada concentração molar para modificar o pH do meio em uma unidade previamente definida (Wolfschoon-Pombo et al., 2012).

Ácidos são substâncias que se ionizam quando em solução aquosa, formando íons $\mathrm{H}^{+}$, ou seja, são doadores de prótons. As bases são substâncias que recebem íons $\mathrm{H}^{+}$e liberam íons $\mathrm{OH}^{-}$quando em solução aquosa. Ao ser adicionar em água, o ácido forte é completamente ionizado como mostra a equação geral abaixo (Equação 1) (Brown et al., 2017).

$$
H A_{(a q)}+H_{2} O_{(\mathbb{Q})} \rightarrow A_{(a q)}^{-}+H_{3} O_{(a q)}^{+} \text {(Eq. 1) }
$$


A adição de um ácido fraco em água resulta em uma dissociação parcial (Equação 2). Neste caso é possível definir a constante de equilíbrio $\left(K_{a}\right)$ da reação de dissociação ácida (Equação 3) (Skoog, Holler \& Crouch, 2016).

$$
\begin{aligned}
& H A_{(a q)}+H_{2} O_{(D)} \leftrightarrow A_{(a q)}^{-}+H_{a} O_{(\llbracket q)}^{+} \text {(Eq. 2) } \\
& K_{\square}=\frac{\left[\mathrm{H}_{3} \mathrm{O}^{+}\right]\left[\mathrm{A}^{-}\right]}{[\mathrm{HA}]} \text { (Eq. 3) }
\end{aligned}
$$

Maiores valores de $\mathrm{K}_{\mathrm{a}}$ indicam maior concentração dos produtos da reação (numerador da equação), ou seja, formação de maior quantidade de íons $\mathrm{H}^{+}$, tendo como consequência, queda no pH da solução. Em contrapartida, menores valores de $\mathrm{K}_{\mathrm{a}}$ indicam maior concentração dos reagentes (denominador da equação), dessa forma, menos íons $\mathrm{H}^{+}$são formados e menor é a alteração no pH da solução. Se a uma solução de ácido ou base fraca e seus sais em equilíbrio é adicionada certa quantidade de ácido $\left(\mathrm{H}^{+}\right)$ou base $\left(\mathrm{OH}^{-}\right)$, o sistema é capaz de deslocar a reação química no sentido de formação de produtos ou reagentes a fim de reestabelecer o equilíbrio (Princípio de Le Châtelier) e evitar que haja uma queda ou aumento brusco no pH da solução, o que é chamado de efeito tampão. Esse efeito tampão é possível devido à baixa taxa de dissociação dos ácidos e bases fracas, o que faz com que as espécies envolvidas ainda estejam disponíveis e sejam capazes de neutralizar certa quantidade de ácido ou base adicionada (Van Slyke, 1922).

Um sistema tampão é sempre formado por um ácido fraco junto de um sal derivado desse ácido (tampão ácido) ou por uma base fraca e um sal derivado dessa base (tampão básico). Cada sistema tampão possui um valor de constante de dissociação $\left(\mathrm{K}_{\mathrm{a}}\right)$ e um valor de $\mathrm{pK}_{\mathrm{a}}\left(\mathrm{pK}_{\mathrm{a}}=-\log \left(\mathrm{K}_{\mathrm{a}}\right)\right)$. O pK $\mathrm{p}_{\mathrm{a}}$ se refere ao valor de $\mathrm{pH}$ no qual o ácido ou base está $50 \%$ em sua forma não dissociada e 50\% na forma dissociada. A Figura 2 representa de forma gráfica a relação entre a diferença do $\mathrm{pH}$ e pKa e o efeito tamponante.

Figura 2. Relação entre a diferença do pH e pKa e o efeito tamponante.

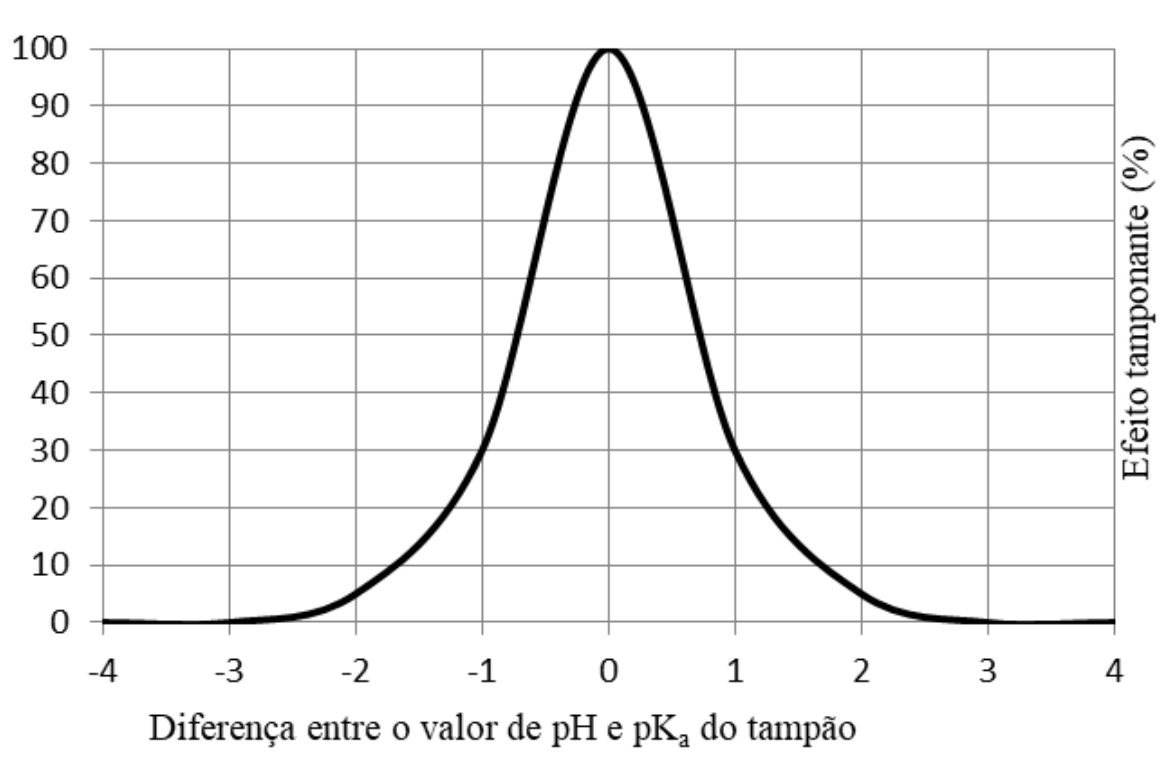

Fonte: Adaptado de Wolfschoon-Pombo et al. (2012).

A capacidade tamponante do sistema é máxima quando a razão entre a concentração do ácido ou base e a concentração do sal é igual a 1, ou seja, quando [ácido/base] = [sal], o que ocorre no valor de $\mathrm{pH}=$ pKa. Como é possível 
observar na Figura 2, quando a diferença entre o pH e o pKa é zero, a capacidade tamponante é de 100\%. Com o aumento dessa diferença, a capacidade tamponante tende a diminuir (Van Slyke, 1922; Wolfschoon-Pombo; Böttger; Lösche, 2012).

A partir da lei de ação das massas, lei fundamental do equilíbrio químico de Guldberg e Waage de 1879, Van Skyle, em 1922, desenvolveu matematicamente o termo de capacidade tamponante ( $\beta$ ) para medir quantitativamente o efeito de uma substância tampão em uma faixa de $\mathrm{pH}$ definida relacionando a derivação do número de equivalentes de ácido ou base necessários para alterar o pH em uma unidade (B) e a variação do pH (Equação 4). A capacidade tamponante é uma função contínua, não linear e possui sempre valor positivo (Van Slyke, 1922; Wolfschoon-Pombo et al., 2012; Wolfschoon-Pombo et al., 2017).

$$
\beta=\frac{\mathrm{dB}}{\mathrm{dpH}}(\text { Eq. 4) }
$$

A capacidade tamponante pode ser descrita de acordo com a Equação 5:

$$
\beta=\beta \mathrm{OH}^{-}+\beta \mathrm{H}^{+}+\Sigma \beta \mathrm{i} \text { (Eq. 5) }
$$

onde os dois primeiros termos se referem à capacidade tamponante da água e o último termo representa o somatório da capacidade tamponante de todos os pares tampão presentes na solução de interesse (Van Slyke, 1922; Wolfschoon-Pombo $e t$ al., 2012).

No leite estão presentes diversos componentes que contribuem de forma diferente para o efeito tamponante como o fosfato solúvel, fosfato de cálcio coloidal, citrato, bicarbonato, caseínas e proteínas do soro de leite. Cada um desses compostos contem um ou mais pares tampão que afetam a capacidade tamponante. Como a capacidade tamponante é obtida a partir da soma das contribuições de cada grupo tampão, este cálculo se torna extramente complexo para o leite, uma vez que nele estão presentes diversos sistemas tamponantes (Kirchmeier, 1980; Salaün et al., 2005; Wolfschoon-Pombo et al., 2012).

No doce de leite, os principais sistemas que podem contribuir para o efeito tamponante são o ácido carbônico/bicarbonato $(\mathrm{pKa}=6,51)$, histidina $(\mathrm{pKa}=6,6), \beta$-caseína-fosfoserina $(\mathrm{pKa}=6,8)$, fosfato $(\mathrm{pKa}=7,2)$ e grupo $\alpha$ amino terminal $(\mathrm{pKa}=7,7)$ (Wolfschoon-Pombo et al., 2012). A capacidade tamponante pode ser determinada através do método de titulações ácido-base e calculada a partir da Equação 6, que relaciona a quantidade de ácido ou base utilizada e a alteração causada no pH da amostra titulada (Whittier, 1929; Salaün et al., 2005; Wolfschoon-Pombo et al., 2012).

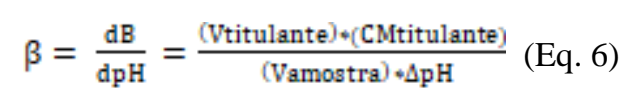

onde: $\mathrm{V}_{\text {titulante }}=$ volume gasto de ácido ou base na titulação (L)

$\mathrm{CM}_{\text {titulante }}=$ concentração molar do titulante $(\mathrm{mol} / \mathrm{L})$

$\mathrm{V}_{\text {amostra }}=$ Volume da amostra titulada $(\mathrm{L})$

$\Delta \mathrm{pH}=$ variação do $\mathrm{pH}$ da amostra

A titulação ácido-base pode ser realizada de diferentes formas: apenas acidificação, apenas alcalinização, ou ainda, acidificação seguida de alcalinização e alcalinização seguida de acidificação. Quando é realizada a titulação ácida seguida pela alcalina, observa-se a intensidade máxima da capacidade tamponante do leite em $\mathrm{pH}$ próximo de 5. Isso ocorre, pois nessa condição o fosfato coloidal é totalmente solubilizado e os fosfatos orgânicos e inorgânicos livres podem se associar ao $\mathrm{H}^{+}$. $\mathrm{Na}$ faixa de pH entre 3 e 4, o valor da capacidade tamponante está relacionado com os aminoácidos ácidos das caseínas e das proteínas do soro. Ao fazer a titulação alcalina do leite acidificado, é comum se pensar que a curva de titulação obtida seja a 
mesma da titulação ácida, porém, isso não acontece. Neste caso, a capacidade tamponante máxima é observada no valor de pH em torno de 6,3 devido a liberação de prótons pela formação de sais insolúveis de fosfato de cálcio. Aminoácidos básicos e íons carbonatos fazem com que haja um efeito tamponante também em torno de pH 9 (Lucey, Hauth, Gorry \& Fox., 1993; Wiley, 1935; Salaün et al., 2005).

Partindo do pH natural do leite rumo à alcalinização, tem-se uma capacidade tamponante baixa em pH entre 8 e 9 , ocorrendo um aumento em valores de pH mais elevados. Nesta faixa, não há influência dos fosfatos orgânicos e inorgânicos, pois o pH é maior que seus valores de pKa. Ao acidificar o leite após a alcalinização, o efeito tampão máximo ocorre no pH igual a 5, porém numa intensidade menor que a intensidade observada quando a acidificação ocorre primeiro que a alcalinização, o que é explicado pela solubilização do fosfato de cálcio coloidal entre sua forma natural e as formas obtidas quando o pH é elevado (Lucey et al., 1993; Wiley, 1935; Salaün et al., 2005).

A plotagem gráfica da relação entre o pH e o valor da capacidade tamponante fornece informações sobre em qual faixa de $\mathrm{pH}$ a capacidade tamponante é máxima e qual a sua intensidade em determinado pH (Van Slyke, 1922; Salaün et al., 2005; Wolfschoon-Pombo et al., 2017).

Carneiro et al. (2020) avaliou a variação entre o pH de leites adicionados da mesma quantidade de quatro diferentes reguladores de acidez (bicarbonato de sódio, carbonato de sódio, sesquicarbonato de sódio e hidróxido de sódio) e o pH de doces de leites fabricados a partir desses leites. Os doces fabricados com adição de hidróxido de sódio apresentaram maior queda no $\mathrm{pH}$ quando comparado com o pH do leite antes do processamento, seguido pelos adicionados de carbonato de sódio, sesquicarbonato de sódio e bicarbonato de sódio. Esses resultados podem indicar que hidróxido de sódio confere menor capacidade tamponante ao leite, uma vez que possui baixa resistência à alteração de $\mathrm{pH}$, enquanto que a adição de bicarbonato de sódio pode resultar em aumento na capacidade tamponante do leite. Um ponto importante a ser observado é que neste trabalho, para que resultados ainda mais confiáveis fossem obtidos, a forma de ideal de comparação seria através da adição da mesma massa molar dos reguladores de acidez ao leite para a fabricação dos doces, e não da mesma massa das substâncias.

\subsection{Reguladores de acidez}

Durante o aquecimento do leite para a fabricação do doce ocorre um aumento na acidez do leite denominado acidez total desenvolvida (ATD), e consequentemente, diminuição do $\mathrm{pH}$ ocasionado por alguns fatores importantes. O primeiro deles é a concentração da acidez natural do leite devido a diminuição do volume causado pela evaporação da água durante o processo de fabricação do DL. Outro fator responsável pela ATD é a degradação das moléculas de lactose causada pela elevada temperatura de aquecimento. A ação do calor também ocasiona a desfosforilação das caseínas e precipitação do fosfato de cálcio, contribuindo com o desenvolvimento a ATD e diminuição do pH. Essa queda de pH tem como consequências a precipitação de proteínas, favorece a cristalização da lactose e prejudica a ocorrência da RM (Penci \& Marín, 2016; Stephani et al., 2019).

Diante disso, o regulador de acidez é considerado um elemento fundamental na tecnologia de fabricação do doce de leite. Embora a legislação permita o uso de outros reguladores de acidez como carbonato de sódio, hidróxido de sódio e hidróxido de cálcio, o bicarbonato de sódio é o mais utilizado nas indústrias (Brasil, 1997a; Ranalli; Andrés \& Califano, 2016). O bicarbonato de sódio corrige a acidez inicial do leite, além de atuar como uma reserva de alcalinidade, neutralizando o ácido lático, formando água, gás carbônico e lactato de sódio (Stephani et al., 2019). Aumentando a acidez do leite acima do ponto isoelétrico das proteínas evita-se a desestabilização das micelas de caseína. Outro efeito da adição do bicarbonato de sódio é a intensificação da RM, que é favorecida na faixa de pH entre 6 e 7. (Penci \& Marín, 2016; Ranalli et al., 2011). A adição de bicarbonato de sódio geralmente é feita em quantidade suficiente para ajustar a acidez do leite para 10 a $13{ }^{\circ}$ Dornic $(0,10$ a 0,13\% de acidez expressa em ácido lático). A utilização de quantidade maior que a necessária de bicarbonato de sódio leva a 
um produto final com coloração muito escura e textura emborrachada (Penci \& Marín, 2016; Ranalli et al., 2011; Stephani et al., 2019).

Blanco et al. (2012) avaliou a influência do pH inicial do leite $(6,0 ; 6,8 ; 7,5)$ no desenvolvimento da cor ao longo do aquecimento do leite e sacarose na produção do doce de leite nos tempos 0, 10, 30 e 60 minutos utilizando o sistema CIELab. Os valores de $\mathrm{pH}$ foram ajustados utilizando hidróxido de sódio ou ácido lático. Foi observado maior desenvolvimento de coloração na amostra de pH inicial igual a 7,5, seguido pela de pH 6,8 e 6,0, confirmando a forte influência do pH na ocorrência da RM. Observou-se também a tendência do aumento da componente vermelha e da cor marrom e diminuição da luminosidade com o aumento do tempo de aquecimento.

Carneiro et al. (2020) estudou a influência da adição de quatro diferentes reguladores de acidez (bicarbonato de sódio, carbonato de sódio, hidróxido de sódio e sesquicarbonato de sódio) em quantidades iguais $\left(0,1 \% \mathrm{~m} \cdot \mathrm{m}^{-1}\right)$ ao leite destinado a fabricação de DL. O leite adicionado de carbonato de sódio apresentou o maior aumento no valor de pH e o adicionado de bicarbonato de sódio, o menor aumento. O leite adicionado de sesquicarbonato de sódio apresentou comportamento intermediário com relação ao valor de pH. A adição de carbonato de sódio ao leite resultou em doces com coloração mais escura e maiores valores de dureza, seguidos dos doces produzidos com sesquicarbonato de sódio, hidróxido de sódio e bicarbonato de sódio. Da mesma forma que observado do tópico anterior (capacidade tamponante), novamente ressalta-se a importância da comparação através da adição da mesma massa molar dos reguladores de acidez, e não da mesma massa das substâncias.

\subsection{Reologia}

A reologia pode ser definida como o estudo do fluxo e deformação de fluidos e materiais e envolve a relação entre a taxa de cisalhamento e a tensão de cisalhamento. Taxa de cisalhamento, normalmente representada pelo símbolo $\ddot{\Upsilon}$, é o gradiente de velocidade estabelecido em um fluido como resultado de uma tensão de cisalhamento aplicada. A tensão de cisalhamento $(\sigma)$ é a razão entre o módulo da força que age tangencialmente sobre um material e a área de aplicação dessa força (Mezger, 2014).

Os alimentos e bebidas são materiais estruturados geralmente formados por uma infinidade de compostos como água, carboidratos, proteínas, lípideos, minerais e fibras. Estes constituintes influenciam significativamente na fluidez e comportamento estrutural, resultando em respostas reológicas complexas. Por ser capaz de fornecer informações detalhadas sobre o comportamento de um alimento, o conhecimento da reologia é de extrema importância em diversos aspectos durante o processamento como o desenvolvimento de novos produtos, dimensionamento de equipamentos, controle de qualidade dos produtos através da minimizaçao de defeitos na textura, avaliação da estabilidade do produto durante sua vida útil e satisfação do consumidor (Ahmed; Ptaszek \& Basu, 2017; Stokes \& Xu, 2019).

O comportamento do fluxo dos materiais pode depender apenas da taxa de cisalhamento e não do tempo de duração desse cisalhamento, classificados como independentes do tempo. Por outro lado, o comportamento reológico pode depender também da duração do cisalhamento, conhecidos como dependentes do tempo. Encaixam-se na classificação de independentes do tempo os fluidos newtonianos, pseudoplásticos, plástico de Bingham e Herschel-Bulkley (Rao, 2013).

De acordo com a lei da viscosidade de Newton $(\sigma=\mu \ddot{\Upsilon})$, a taxa de cisalhamento $(\ddot{\Upsilon})$ e a tensão de cisalhamento $(\sigma)$ são grandezas diretamente proporcionais e a viscosidade $(\mu)$ é a constante de proporcionalidade. Os fluidos que se comportam de acordo com essa relação e não necessitam de uma tensão de cisalhamento inicial para escoar são chamados de fluidos newtonianos e possuem viscosidade constante. São exemplos de fluidos newtonianos a água, ar, óleo, solução salina, glicerina, entre outros (Mezger, 2014). 
Para os fluidos não-newtonianos, classificação onde se encontram a maior parte dos alimentos, essa relação não é linear e a viscosidade depende da intensidade da tensão de cisalhamento aplicada. A lei da potência (Equação 7) pode ser utillizada para descrever a reação de um fluido à deformação (Stokes \& Xu, 2019).

$$
\sigma=\mathrm{K} * \mathbb{Y}^{\mathrm{n}} \text { (Eq. 7) }
$$

onde, $\sigma=$ tensão de cisalhamento;

$\mathrm{K}=$ índice de consistência;

$\ddot{\Upsilon}=$ taxa de cisalhamento;

$\mathrm{n}=$ índice da lei da potência;

Os fluidos podem ser classificados de acordo com o valor de n:

$\mathrm{n}=1$ : fluido newtoniano

$\mathrm{n}<1$ : fluido pseudoplástico

$\mathrm{n}>1$ : fluido dilatante

Os fluidos pseudoplásticos são aqueles que diante de uma taxa de cisalhamento crescente, tem sua viscosidade aparente diminuída. Já para os dilatantes, a viscosidade aparente aumenta com o aumento da taxa de cisalhamento. Ambos os fluidos não necessitam de uma tensão de cisalhamento inicial para escoar e não são dependentes do tempo de cisalhamento. $\mathrm{O}$ termo viscosidade aparente é usado, pois, diferente dos fluidos newtonianos, a viscosidade passa a ser dependente da taxa de cisalhamento (Stokes \& Xu, 2019).

O fluxo de alguns materiais pode não ter início até que um valor mínimo de tensão de escoamento seja alcançado, ou seja, o escoamento do fluido é dependente de uma tensão de cisalhamento inicial. Quando a relação entre a taxa de cisalhamento e a tensão de cisalhamento é linear após vencida a tensão inicial, diz-se que o material se comporta de acordo com o modelo de plástico de Bingham, descrito pela Equação 8. Concentrados de tomate, ketchup, mostarda e maionese são alimentos que apresentam esse comportamento (Rao, 2013).

$$
\sigma=\sigma_{0}+K \bar{r} \quad \text { (Eq. 8) }
$$

onde, $\sigma_{0}=$ tensão de cisalhamento inicial;

Nos casos de uma relação não linear, o comportamento do fluido pode ser descrito pelo modelo de Herschel-Bulkley (Equação 9) (Rao, 2013).

$$
\sigma=\sigma_{0}+K * \ddot{\Upsilon}^{n} \text { (Eq. 9) }
$$

O modelo de Herschel-Bulkey é considerado por diversos autores como modelo adequado para o estudo reológico de DL (Hough, Moro, Segura \& Calvo, 1988; Pauletti, Venier, Sabbag \& Stechina,1990; Ranalli et al., 2011, 2016; Rovedo, Viollaz \& Suarez, 1991). Quando se diz respeito aos fluidos que possuem comportamento do fluxo dependente do tempo, pode-se citar os tixotrópicos e reopéticos. Os tixotrópicos apresentam diminuição da viscosidade aparente com o tempo de cisalhamento, a uma taxa de cisalhamento constante, enquanto que os reopéticos apresentam aumento na viscosidade aparente (Rao, 2013). 
Diversos alimentos são classificados como fluidos viscoelásticos, ou seja, apresentam propriedades sólido-elásticas e líquido-viscosas. Dois parâmetros são utilizados para estudar o comportamento viscoelástico: o módulo de armazenamento (G') e o módulo de perda (G'). De forma simplificada, quando $G^{\prime}>G^{\prime}$ ', pode-se dizer que o material se comporta como um sólido viscoelástico, enquanto G'>G', indica que o material se comporta como um fluido viscoelástico (Stokes \& Xu, 2019).

Durante a fabricação do DL, a evaporação promove alterações fisico-químicas e estruturais, uma vez que a remoção da água reduz o espaçamento entre as partículas como glóbulos de gordura, proteínas, micelas de caseína e lactose. Essas modificações influenciam grandemente no comportamento reológico do produto final (Ranalli et al., 2016).

Por ser um produto bastante regional, poucos estudos são publicados acerca do comportamento reológico de DL. Pauletti et al. (1990) e Navarro, Ferrero e Zaritzky (1999) concluiram a partir de testes oscilatórios que o DL apresenta um comportamento reológico intermediário ao de uma solução concentrada e um gel, dependendo do teor de sólidos e tipo do doce.

Hough et al. (1988) avaliaram as propriedades do escoamento de doces de leite durante a produção com teor de sólidos entre 55 e $70 \%$ e a temperaturas entre 25 e $70{ }^{\circ} \mathrm{C}$. A tixotropicidade dos doces foi avaliada a partir do modelo de Weltmann e foi observado que quanto maior o teor de sólidos e menor a temperatura, o comportamento do DL se aproxima mais de um fluido tixotrópico. Constatou-se que a tensão de cisalhamento inicial (cisalhamento mínimo para escoamento - $\sigma_{0}$ ) e o índice de consistência $(\mathrm{K})$ dos doces diminuiram com o aumento da temperatura e aumentaram com o aumento do teor de sólidos. De acordo com os autores, o DL pode ser considerado um fluido pseudoplástico.

Rovedo et al. (1991) estudaram o efeito do pH e da temperatura na reologia de doces de leite para confeitaria e consumo direto e observaram que ambas as categorias apresentaram características tixotrópicas e pseudoplásticas. O experimento mostra também que a viscosidade aparente dos doces diminuiu com o aumento da temperatura. Com relação ao $\mathrm{pH}$, doces com pH básico $(8,3)$ apresentaram maior viscosidade aparente, seguido dos doces com pH original $(6,1)$ e pH ácido $(3,0)$. Além disso, os autores concluiram que o DL para confeitaria é mais consistente e mais pseudoplástico quando comparado ao tradicional devido à utilização de amido em sua fabricação.

Ranalli et al. (2011) realizaram a caracterização reológica de diferentes amostras comerciais de DL tradicional, para confeitaria e com redução de calorias e gordura. Apesar de todos apresentarem o comportamento pseudoplástico, foram encontradas diferenças significativas no comportamento reológico das amostras. Foi observado que os módulos de perda e armazenamento do DL para confeitaria foi maior que os do DL tradicional devido à presença de amido na formulação (aumento na elasticidade).

Ranalli et al. (2016) estudaram as propriedades reológicas de amostras de DL com baixo teor de gordura e diferentes teores de água e goma xantana. Curvas de fluxo em estado estacionário (viscosidade x tensão de cisalhamento) foram obtidas a

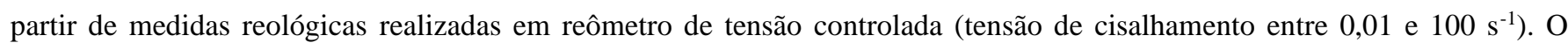
modelo de Herschel-Bulkley foi utilizado para modelar as curvas e calcular os parâmetros correspondentes. Os doces de leite produzidos demonstraram comportamento pseudoplástico. Doces de leite com menores teores de água apresentaram maior índice de consistência $(\mathrm{K})$ e tensão de cisalhamento inicial $\left(\sigma_{0}\right)$, enquanto que nos adicionados de goma xantana foi observado o comportamento contrário. Os autores relatam que mudanças no teor de água dos doces influenciaram mais os parâmetros de Herschel-Bulkley se comparada às alterações causadas pela adição da goma xantana.

\subsection{Textura}

A textura tem sido considerada um dos mais importantes atributos alimentares e possui grande contribuição para a qualidade e aceitação dos produtos pelos consumidores (Gavahian, Tiwari, Chu, Ting \& Farahnaky, 2019; Nishinari \& Fang, 2018). Além de influenciar na qualidade e aceitabilidade dos alimentos, a textura também está relacionada com a saciedade, 
uma vez que alimentos de textura mais complexa exigem um tempo de processamento oral mais longo que os de textura menos complexa, gerando a sensação de saciedade (Guimarães et al., 2020).

A textura é um conjunto de percepções sentidas pelo corpo humano resultante do contato do alimento com a boca ou durante a manipulação com as mãos (Joyner (Melito), 2018). Segundo a NBR ISO 11036 (Associação Brasileira De Normas Técnicas, 2017), a textura pode ser definida ainda como "o conjunto de propriedades mecânicas, geométricas, de superfície e de corpo de um produto, perceptíveis pelos receptores cinestésicos e somestésicos e, quando apropriado, pelos receptores visuais e auditivos, a partir da primeira mordida até a deglutição final”. A somestesia (sentido tátil da pele) reconhece a umidade, gordura e partículas geométricas. Já a cinestesia (força dos músculos) identifica as propriedades mecânicas e respostas á mastigação e manipulação do alimento (Liu, Y., Cao \& Liu, G., 2019).

\subsection{TPA (textural profile analysis - análise do perfil de textura)}

Diversos métodos podem ser utilizados na avaliação da textura dos alimentos através da simulação de ações como mordida, corte, alongamento e mastigação. Um dos métodos mais comuns e mais utilizados é a analise do perfil de textura (TPA). O seu princípio de funcionamento se baseia em realizar a compressão uniaxial da amostra em dois ciclos, simulando o movimento da mandíbula durante as duas primeiras mordidas em um alimento, para a avaliação de parâmetros como dureza, coesividade, elasticidade, gomosidade, mastigablidadade e adesividade. A partir de um software, é gerada uma curva que relaciona a carga e o tempo da análise (Nishinari, Fang \& Rosenthal., 2019; Liu et al., 2019).

A Tabela 2 mostra as definições de cada um dos atributos, de acordo com a NBR ISO 11036 (Associação Brasileira De Normas Técnicas, 2017):

Tabela 2. Definições dos atributos de textura.

\begin{tabular}{ll}
\hline \multicolumn{1}{c}{ Atributo } & \multicolumn{1}{c}{ Definição } \\
\hline Dureza & força necessária para penetrar ou deformar um alimento \\
Coesividade & quanto o alimento é capaz de se deformar antes da ruptura \\
Elasticidade & $\begin{array}{l}\text { capacidade do alimento em retornar à sua condição inicial após uma } \\
\text { deformação } \\
\text { força para desintegrar um alimento para a deglutição }\end{array}$ \\
Mastigabilidade & tempo ou número de mastigações necessárias para que o alimentos esteja \\
& apto para a deglutição \\
Adesividade & força necessária para remover um alimento aderido na boca
\end{tabular}

Fonte: Associação Brasileira De Normas Técnicas (2017).

Na Figura 3 está representado um esboço da curva gerada ao fim da análise TPA. 
Figura 3. Esboço da curva de textura.

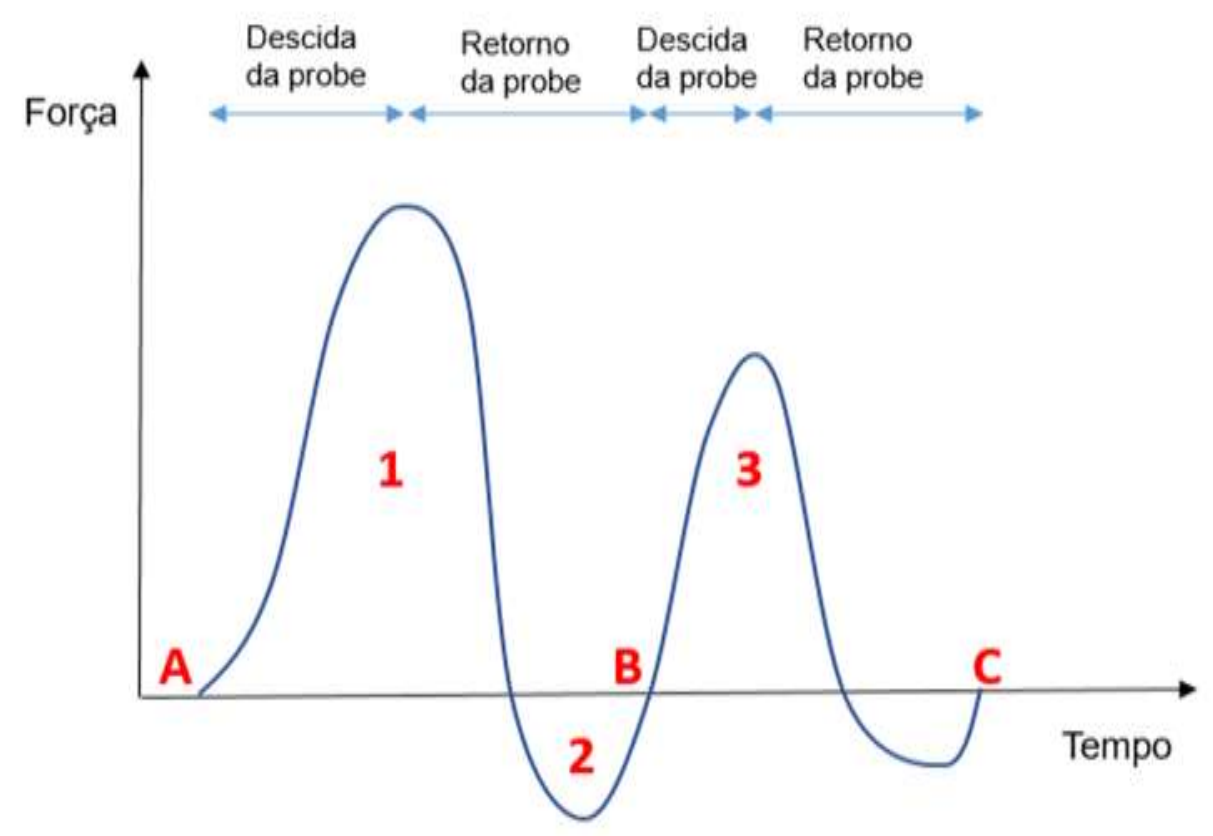

Fonte: Adaptado de Liu et al. (2019).

O ponto A representa o ínicio da análise, ou seja, a primeira compressão do alimento. O intervalo de A até B corresponde ao primeiro ciclo e o intervalo de $\mathrm{B}$ a $\mathrm{C}$, o segundo ciclo. O primeiro e o segundo picos da curva representam os valores de dureza do primeiro e segundo ciclo, respectivamente. A área da região 2 equivale ao valor de adesividade e a razão entre a área da região 1 e a área da região 3 (A1/A3) resulta no valor de coesividade. O intervalo entre B e C se refere à elasticidade do produto (Liu et al., 2019).

Alguns pontos importantes devem ser levados em consideração no momento da execução da análise do perfil de textura com o objetivo de garantir a confiabilidade dos resultados. Antes do início da análise é necessário estabelecer quais parâmetros serão avaliados, uma vez que nem todos os parâmetros são aplicáveis para todos os tipos de produto. É preciso também certificar-se de que a amostra não sofreu nenhum tipo de perturbação que altere a sua estrutura, pois interferências na amostra podem alterar a resposta às compressões. Por se tratar de um método que simula a mastigação, a velocidade de compressão é um importante parâmetro e deve ser similar à velocidade de mastigação dos seres humanos. O tamanho da probe utilizada na análise também pode influenciar nos resultados, por isso é importante avaliar o formato e tamanho da probe de acordo com cada tipo de amostra (Joyner (Melito), 2018; Nishinari et al., 2019).

O DL possui uma textura característica que influencia fortemente na aceitação dos consumidores, por isso, a avaliação da textura é de extrema relevância no desenvolvimento e controle de processos, controle de qualidade e padronização do produto (Ranalli et al., 2011). A textura do DL pode ser bastante variável de acordo com o produto que se deseja obter e as tecnologias aplicadas, como é o caso do DL para confeitaria que apresenta maior viscosidade que o DL para consumo direto. A adição de substâncias como amido, gomas, substituição de parte da sacarose por glicose e a quantidade de regulador de acidez adicionada influenciam na textura do produto final (Penci \& Marín, 2016; Ranalli et al., 2016). A textura do DL pode ser estudada através do analisador de textura e os parâmetros comumente avaliados são os de dureza, capacidade de expansão, aderência, coesão e elasticidade (Penci \& Marín, 2016). 


\subsection{Arenosidade em doce de leite}

Durante a fabricação do DL, o leite é concentrado resultando na saturação e da lactose e da sacarose. Além disso, ao final do processo, com o resfriamento do doce, a solubilidade da lactose é reduzida. Diante desses dois fatores, ao longo do armazenamento são formados cristais de lactose que quando perceptíveis ao paladar configuram um dos principais defeitos relatados em DL. A presença dos cristais de lactose no doce confere ao produto uma textura arenosa, influenciando negativamente na aceitação do consumidor (Stephani et al., 2019).

Esse defeito pode ser amenizado através da indução da cristalização pela adição de núcleos de cristalização objetivando a formação de cristais de tamanhos menores. A produção de doces de leite mais viscosos também é uma maneira de controle da formação de cristais, podendo ser utilizados aditivos espessantes a fim de atingir a viscosidade desejada. Outra alternativa para conter a formação de cristais é a partir da hidrólise parcial ou total da lactose através da adição da enzima $\beta$ galactosidase (lactase), entretanto, essa técnica resulta em importantes alterações tecnológicas que devem ser levadas em consideração, como por exemplo, a coloração do DL. (Penci \& Marín, 2016; Stephani et al., 2019).

A cristalização é um processo que ocorre em duas etapas: a primeira etapa é a chamada nucleação, na qual são gerados novos cristais. Em seguida, ocorre o crescimento dos cristais. A nucleação pode ocorrer a partir de dois métodos, a nucleação primária ou secundária (Stephani et al., 2019). Segundo Schuck (2011), a nucleação primária é o aparecimento de núcleos de uma determinada molécula sem que haja a presença de cristais dessa molécula, enquanto que a nucleação secundária caracteriza-se pela formação de núcleos quando na presença de cristais preexistentes da molécula. De acordo com Fox (1998), a textura arenosa é perceptível ao paladar quando os cristais excedem o tamanho de $16 \mu$ m. Já para Walstra, Geurts, Noomen, Jellema e Van Boekel (2001), a arenosidade é percebida quando os cristais de lactose apresentam tamanho maior que $10 \mu \mathrm{m}$.

Giménez, Ares e Gámbaro (2008) avaliaram a percepção dos consumidores a respeito da arenosidade em DL. Sete amostras de DL foram analisadas sensorialmente por painel treinado, sendo uma amostra sem cristais de lactose e seis amostras com diferentes níveis de cristalização. O tamanho dos cristais variou entre 109 e $138 \mu \mathrm{m}$ e o número de cristais variou entre $10^{7}$ e $1,2 \times 10^{8}$ cristais/grama de doce. As análises mostraram que a reação dos consumidores à arenosidade é heterogênea. Ainda segundo os autores, a percepção da textura arenosa depende do número e tamanho dos cristais de lactose e dos aglomerados de cristais.

Martinez, Hough e Contarini (1990) estudaram a influência de fatores como temperatura, tempo de agitação, concentração da semeadura e formulação do DL na eficiência da indução da cristalização por adição de microcristais de lactose no controle da arenosidade em DL. Através de avaliação sensorial por painel treinado, concluiu-se que a semeadura a $40^{\circ} \mathrm{C}$, agitação por 5 minutos e concentração de microcristais de $6 \mathrm{~g} \cdot 100 \mathrm{~kg}^{-1}$ de DL foram parâmetros eficazes na eliminação da arenosidade ao longo do armazenamento do DL. Entre 15 e 180 dias de armazenamento, o tamanho dos cristais variou entre 4 e $15 \mu \mathrm{m}$ e o número de cristais variou entre $3 \times 10^{8}$ e $8 \times 10^{6} /$ grama de doce.

Sabioni, Pinheiro, Silva, Chaves e Borges (1984a) investigaram a viabilidade do controle de cristalização em DL através da atividade da enzima $\beta$-galactosidase de células permeabilizadas de Kluyveromyces lactis. As células permeabilizadas foram adicionadas em concentrações entre 400 e $800 \mathrm{mg} /$ litro de leite e a atividade enzimática máxima foi observada a $45{ }^{\circ} \mathrm{C}$. A hidrólise da lactose do leite através da atividade da enzima $\beta$-galactosidase de células permeabilizadas de $K$. lactis evitou o desenvolvimento de cristais durante o período de armazenamento de 120 dias: os doces de leite que passaram pela hidrólise da lactose foram avaliados sensorialmente como "sem cristalização perceptível" durante 30, 60, 90 e 120 dias, enquanto que na amostra controle, os cristais já começaram a ser percebidos com 30 dias de armazenamento. Portanto, esta alternativa foi considerada eficiente, simples e econômica no controle da cristalização em DL. Sabioni, Silva, Pinheiro, Borges e Chaves (1984b) estudaram também a viabilidade da prevenção da cristalização em DL através da hidrólise da lactose a partir do 
inóculo de Kluyveromyces lactis no leite a ser utilizado na fabricação dos doces. O crescimento de $K$. lactis foi eficiente no controle da cristalizaçao, não sendo observada formação de cristais ao longo de 120 dias de armazenamento. Entretanto, foram observadas desvantagens no método como requisitos na preparação do inóculo, risco de contaminção e tempo de processo.

A partir de amostras de DL adicionadas de grãos de areia em diferentes granulometrias, Hough, Martinez e Contarini (1990) desenvolveram uma escala de percepção sensorial de arenosidade em função do tamanho e número de cristais de lactose. Foi estudado também o limiar de detecção de arenosidade. Cristais de tamanho igual ou menor que $15 \mu \mathrm{m}$ não foram percebidos. Os cristais de tamanho igual a $45 \mu \mathrm{m}$ foram percebidos quando o número de cristais estava entre $10^{5}$ e $10^{7}$ cristais. Os cristais de tamanho $105 \mu \mathrm{m}$ foram perceptíveis ao paladar quando o número de cristais estava entre $4 \times 10^{3}$ e $10^{5}$ cristais. Os autores concluiram então que o limiar de detecção de arenosidade é variável e depende do tamanho e número de cristais de lactose presentes no DL.

\section{Conclusão}

A partir dos estudos realizados e da revisão de literatura desenvolvida, conclui-se que atributos como $\mathrm{pH}$ e temperatura, reação de Maillard e os fatores que a influenciam, capacidade tamponante do leite e o uso dos reguladores de acidez são essenciais para o controle das características do produto final como cor, aroma, sabor, viscosidade e textura. Por se tratar de um produto tipicamente latino americano, percebe-se que o grande volume dos trabalhos desenvolvidos sobre o doce de leite ocorreu nos países dessa região. Visando a ampliação do conhecimento técnico e científico em doce de leite sugere-se para trabalhos de pesquisa futuros interrelacionar as propriedades $\mathrm{pH}$ e poder tamponante do leite após adição do redutor de acidez com os atributos viscosidade e textura.

\section{Agradecimentos}

À Universidade Federal de Viçosa, à Universidade Federal de Juiz de Fora (Departamento de Química e Faculdade de Farmácia), à CAPES (001) e ao Conselho Nacional de Desenvolvimento Científico e Tecnológico (CNPq) pelas bolsas de produtividade 307334/2020-1 e 315337/2018-4.

\section{Referências}

Ahmed, J.; Ptaszek, P. \& Basu, S. (2017). Food Rheology: Scientific Development and Importance to Food Industry. Food Science, Technology and Nutrition, $1-4$.

ABNT NBR ISO 11036, de 28 de agosto de 2017. Análise sensorial - Metodologia - Perfil de textura. Associação Brasileira De Normas Técnicas.

Bertrand, E., Boustany, E. P., Faulds, C. \& Berdagué, J. (2018). The maillard reaction in food: an introduction. Reference Module in Food Science, 1-10.

Blanco, A. R., Piagentini, A., Rozycki, S., Lema, A., Pauletti, M. S. \& Panizzolo, L. A. (2012). Evolución del desarrollo del color en sistema modelo de composición similar al dulce de leche. Influencia del tiempo de calentamiento y del pH. Revista Del Laboratorio Tecnológico Del Uruguay. 7 .

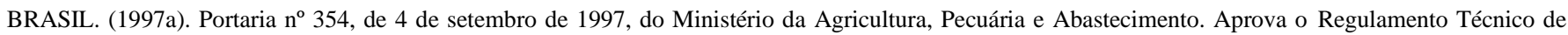
Identidade e Qualidade de Doce de Leite. Diário Oficial da República Federativa do Brasil.

BRASIL. (1997b). Portaria SVS/MS no 540, de 27 de outubro de 1997, do Ministério da Saúde. Secretaria de Vigilância Sanitária. Aprova o Regulamento Técnico: Aditivos Alimentares - definições, classificação e emprego. Diário Oficial da República Federativa do Brasil.

Brown, T. L., Lemay, H. E., Bursten, B. E., Murphy, C., Woodward, P. \& Stoltzfus, M. E. (2017). Chemistry: The central science. (14a ed.), Pearson.

Carneiro, L. C. M., Perrone, I. T., Pinto, C. B. A., Oliveira, L. F. C., Wolfschoon-Pombo, A. F., Carvalho, A. F. \& Stephani, R. (2020). Influência de diferentes reguladores de acidez na estabilização coloidal do leite e nas características físico-químicas de doce de leite. Indústria de Laticínios, 142 , 68-74.

Damodaran, S., Parkin, K. L., Fennema, O. R. (2008). Fennema's Food Chemistry. (4a ed.), CRC Press/Taylor \& Francis.

Francisquini, J. D., Rocha, J., Martins, E., Stephani, R., Silva, P. H. F., Renhe, I. R. T., Perrone, I. T. \& Carvalho, A. (2019). 5-Hydroxymethylfurfural formation and color change in lactose-hydrolyzed Dulce de leche. Journal of Dairy Research, 86, 477-482. 
Francisquini, J. D., Martins, E., Silva, P. H. F., Shuck, P., Perrone, I. T. \& Carvalho, A. F. (2017). Reação de maillard: uma revisão. Revista do Instituto de Laticínios Cândido Tostes 72 (1), 48-57.

Fox, P. F. (1998). Developments in Dairy Chemistry - 3: Lactose and Minor Constituents. (2a ed.), Elsevier Applied Science Publishers.

Gavahian, M., Tiwari, B. K., Chu, Y., Ting, Y. \& Farahnaky, A. (2019). Food texture as affected by ohmic heating: Mechanisms involved, recent findings, benefits, and limitations. Trends in Food Science and Technology, 86, 328-339.

Gaze, L. V., Costa, M. P., Monteiro, M. L. G., Lavorato, J. A. A., Junior, C. A. C., Raices, R. S. L., Cruz, A. G. \& Freitas, M. Q. (2015). Dulce de Leche, a typical product of Latin America: characterisation by physicochemical, optical and instrumental methods. Food Chemistry, $169,471-477$.

Giménez, A., Ares, G. \& Gámbaro, A. (2008). Consumer perception of sandiness in dulce de leche. Journal of Sensory Studies, 23 , $171-185$.

Guimarães, J. T., Balthazar, C. F., Silva, R., Rocha, R. S., Graça, J. S., Esmerino, E. A., Silva, M. C., Sant'Ana, A. S., Duarte, M. C. K. H., Freitas, M. Q. \& Cruz, A. G. (2020). Impact of probiotics and prebiotics on food texture. Current Opinion in Food Science, 33, 38-44.

Hough, G., Moro, O., Segura, J. \& Calvo, N. (1988). Flow properties of dulce de leche, a typical argentine dairy product. Journal of Dairy Science, 71 (7), 1783-1788.

Hough, G., Martinez, E. \& Contarini, A. (1990). Sensory and objective measurement of sandiness in dulce de leche, a typical Argentine product. Journal of Dairy Science, 73, 604-611.

Joyner, H. S. (2018). Explaining food texture through rheology. Current Opinion in Food Science, 21, 7-14.

Kirchmeier, O. (1980). Buffer capacities and buffer equilibrium of milk. Milchwissenschaft, 35, 667-670.

Liu, Y. X., Cao, M. J., \& Liu, G. M. (2019). Texture analyzers for food quality evaluation. In Evaluation Technologies for Food Quality (pp. 441-463). Woodhead Publishing.

Lucey, J. A., Hauth, B., Gorry, C. \& Fox, P. F. (1993). The acid-base buffering properties of milk. Milchwissenschaft, 48, 268-272.

Lund, M. N. \& Ray, C. A. (2017). Control of maillard reactions in foods: strategies and chemical mechanisms. Journal of Agricultural and Food Chemistry, 65 (23), 4537-4552.

Martinez, E., Hough, G. \& Contarini, A. (1990). Sandiness prevention in dulce de leche by seeding with lactose. Journal of Dairy Science, 73 (3), $612-616$.

Mezger, T. G. (2014). The rheology handbook. (4a ed.), Vicentz Network, 2014.

Navarro, A. S., Ferrero, C. \& Zaritzky, N. E. (1999). Rheological characterization of dulce de leche by dynamic and steady shear measurement. Journal of Texture Studies, 30, 43-58.

Nishinari, K. \& Fang, Y. (2018). Perception and measurement of food texture: Solid foods. Journal of Texture Studies, 49 (2), $160-201$.

Nishinari, K., Fang, Y. \& Rosenthal, A. (2019). Human oral processing and texture profile analysis parameters: bridging the gap between the sensory evaluation and the instrumental measurements. Journal of Texture Studies, 50 (5),369-380.

Nooshkam, M., Varidi, M. \& Bashash, M. (2019). The Maillard reaction products as food-born antioxidant and antibrowning agents in model and real food systems. Food Chemistry, 275, 644-660.

Pauletti, M., Venier, A., Sabbag, N. \& Stechina, D. (1990). Rheological characterization of dulce de leche, a confectionery dairy product. Journal of Dairy Science. 73 (3), 601-603.

Penci M. \& Marin, M. (2016). Dulce de leche: technology, quality, and consumer aspects of the traditional milk caramel of south america. Traditional Foods, $123-136$.

Penci, M. C., \& Marín, M. A. (2016). Dulce de leche: Technology, quality, and consumer aspects of the traditional milk caramel of South America. In Traditional foods (pp. 123-136)

Pinto, A. P. E. F., \& Wolfschon-Pombo, A. (1984). 5-Hidroximetilfurfural no doce de leite. Revista do Instituto de Laticínios Cândido Tostes, $39,09-11$.

Ranalli, N., Andrés, S. C. \& Califano, A. N. (2011). Physicochemical and rheological characterization of dulce de leche. Journal of Texture Studies, 43 (2), $115-123$.

Ranalli, N., Andrés, S. C., \& Califano, A. N. (2016). Rheological Behavior of Low-Fat Dulce De Leche with Added Xanthan Gum. Journal of Food Processing and Preservation, 41(4), 1-8.

Rao, M. A. (2013). Rheology of fluid, semisolid and solid foods: Principles and applications. (3a ed.), Springer.

Rovedo, C. O., Viollaz, P. E., \& Suarez, C. (1991). The effect of pH and temperature on the rheological behavior of Dulce de leche, a typical dairy Argentine product. Journal of dairy science, 74(5), 1497-1502.

Sabioni, J. G., Pinheiro, A. J. R., Silva, D. O., Chaves, J. B. P., \& Borges, A. C. (1984a). Control of lactose crystallization in "dulce de leche” by beta-Dgalactosidase activity from permeabilized Kluyveromyces lactis cells. Journal of dairy science, 67(10), 2210-2215.

Sabioni, J. G., Silva, D. O., Pinheiro, A. J. R., Borges, A. C., \& Chaves, J. B. P. (1984b). Control of Lactose Crystallization in "Dulce de Leche" by Kluyveromyces lactis Fermentation. Journal of Dairy Science, 67(8), 1694-1698. 
Research, Society and Development, v. 10, n. 11, e155101119408, 2021

(CC BY 4.0) | ISSN 2525-3409 | DOI: http://dx.doi.org/10.33448/rsd-v10i11.19408

Salaün, F., Mietton, B., \& Gaucheron, F. (2005). Buffering capacity of dairy products. International Dairy Journal, 15(2), 95-109.

Schuck, P. (2011). Lactose Crystallization. Encyclopedia of Dairy Sciences. Oxford: Academc Press, (2a ed.), 3, 182 -185.

Skoog, D. A; Holler, F. J.; Crouch, S. R. (2016). Principles of instrumental analysis. (7a ed.), Cengage Learning.

Starowicz, M. \& Zieliński, H. (2019). How maillard reaction influences sensorial properties (color, flavor and texture) of food products? Food Reviews International, 35 (8), 707-725.

Stephani, R., Francisquini, J., Perrone, Í. T., de Carvalho, A. F., \& de Oliveira, L. F. C. (2019). Dulce de Leche - chemistry and processing technology. In Milk Production, Processing and Marketing (pp. 1-18). London: IntechOpen.

Stokes, J. R. \& Xu, Y. (2019). Rheology of Food Materials: Impact on and Relevance in Food Processing. Reference Module in Food Science.

Tan, R. (2009). Manufacture of sweetened condensed milk and significance of lactose. In P. F. Fox \& P. L. H. McSweeney (Eds.), Advanced dairy chemistry: lactose, water, salts and minor constituents. (4a ed.), 3. Thomson Science.

Van Slyke, D. D. (1922). On the measurement of buffer values and on the relationship of buffer value to the dissociation constant of the buffer and the concentration and reaction of the buffer solution. The Journal of Biological Chemistry, 52, 525-570.

Walstra, P., Geurts, T. J., Noomen, A., Jellema, A. \& Van Boekel, M, A, J. S. (2001). Ciencia de la Leche y Tecnología de los Productos Lácteos. Zaragoza: Editora Acribia.

Whittier, E. O. (1929). Buffer intensities of milk and milk constituents. Journal of Biological Chemistry, 83, 79-88.

Wiley, W. J. (1935). A study of the titratable acidity of milk - II. The buffer curves of milk. Journal of Dairy Research, 6, 86-90.

Wolfschoon-Pombo, A., Böttger, D., \& Lösche, K. (2012). Pufferkapazität mikrofiltrierter Magermilchkonzentrate. Chemie-Ingenieur-Technik, 84 (4),465474.

Wolfschoon-Pombo, A. F., Spiegel, T. L. \& Hernandez-Zenil, E. (2017). Buffering curves of ideal whey fractions obtained from a cascade membrane separation process. International Journal of Dairy Technology, 70 (2), 287-296. 